\title{
Determination of Interstrand Contact Resistance from Loss and Field Measurements in LHC Dipole Prototypes and Correlation with Measurements on Cable Samples
}

\author{
R. Wolf, D. Leroy, D. Richter, A. P. Verweij, and L. Walckiers \\ CERN, CH-1211 Geneva 23, Switzerland
}

\begin{abstract}
Loss and field errors due to ramping in LHC accelerator dipole magnets are mainly determined by the contact resistance between the strands of the magnet cable. It is therefore important to develop cables having sufficiently high contact resistance in the magnets in order to ease operation of the future LHC collider during ramping. In this paper the contact resistance $R_{c}$ and its distribution in the magnet windings are determined for several dipole prototypes using both the measured loss and field errors during ramping of the magnet. We compare these results with interstrand contact resistance measurements made on short samples of the cables used in these magnets.
\end{abstract}

\section{INTRODUCTION}

The coils of superconducting accelerator dipole magnets like the ones designed for the future LHC proton-proton collider are usually made with Rutherford type cables consisting of two layers of twisted strands. The contact resistance $R_{c}$ between crossing strands (or its inverse the contact conductance $G_{c}$ ) is an important parameter in the cable design. It influences the magnet behaviour in the following ways:

- Interstrand coupling currents over a twist pitch, when the field is changed, give field errors in the aperture and losses in the windings which are proportional to $\mathrm{G}_{\mathrm{c}}$ and depend also on the distribution of $\mathrm{G}_{\mathrm{c}}$ in the coil. To limit the field errors in the LHC dipole we require an $R_{c}$ greater than $10 \mu \Omega$ which will give conductance differences of less than 0.1MS between parts of the magnet coils[1], [2]. Losses may cause quenches during ramping if locally $G_{c}$ is very high.

- The contact resistance has an influence on the current redistribution (during field change) between strands over lengths longer than the twist pitch[3]. The ends of the magnet for instance are believed to generate a current unbalance in the strands proportional to $\sqrt{G_{c}}$, and may be partially responsible for the change of the field error with time observed in accelerators at injection.

The contact resistance in the magnet depends on many factors [4], [5], which are of course more easily studied on short cable samples than in complete magnets. We therefore made a study to see if we could correlate the $R_{c}$ values found in magnet coils with those measured on short cable samples. At the same time we wanted to check if average $R_{c}$ values measured with different methods (loss and field measurements) in the magnets gave the same result. Of particular interest to us is the measurement of the Rc distribution because of its influence on the field quality. We could so verify that the specification on the allowed conductance differences inside the magnet coils were reasonable.

We have performed our analysis on 12 model magnets that have been built by CERN, both single and double aperture $1 \mathrm{~m}$ long models and five $10 \mathrm{~m}$ long two aperture models [6], [7], [8], [9]. The $\mathrm{R}_{\mathrm{c}}$ distribution inside the magnet coils was studied on four of the $10 \mathrm{~m}$ models.

Manuscript received August 27, 1996.

\section{CONTACT RESISTANCES IN MAGNETS}

A. Measuring Methods

CALCULATED FIELD ERRORS DUE TO INTERSTRAND EDDY CURRENTS IN 10M LHC DIPOLE MODELS ASSUMING A CONTACT RESISTANCE (RC) 10M LHC DIPOLE MODELS ASSUMING A CONTACT RESIST
BETWEEN CROSSING STRANDS OF $10 \mathrm{M} \Omega$.

\begin{tabular}{cc}
\hline $\begin{array}{c}\text { Harmonic } \\
\text { number }\end{array}$ & Field(T) at $\mathrm{x}=1 \mathrm{~cm}$ at a ramprate of $6.7 \mathrm{mT} / \mathrm{s}(10 \mathrm{~A} / \mathrm{s})$ \\
\hline 1 & $5.66 \mathrm{E}-04$ \\
3 & $1.80 \mathrm{E}-05$ \\
5 & $-1.84 \mathrm{E}-06$ \\
7 & $-1.16 \mathrm{E}-09$ \\
9 & $4.06 \mathrm{E}-08$ \\
\hline
\end{tabular}

The $R_{c}$ values in the windings of the dipole model magnets are derived with two different methods. The first method, based on loss evaluation by means of voltage and current measurements on the magnet coils [10] during cycling, gives an average $R_{c}$ for the whole magnet and approximate values for the two poles. The second method, based on field measurements during ramping [11] of the magnet, can in addition give more detailed information about the distribution of the contact resistance inside the magnet. We describe the magnetic method in more detail here. During ramping of the magnet the change in higher order field error harmonics are measured with help of a $75 \mathrm{~cm}$ long rotating coil, while the change in the total field, including the main dipole component, is measured with narrow $1.5 \mathrm{~m}$ long and $10 \mathrm{~mm}$ wide stationary coils near the axis of the magnet. This last measurement is important since the calculated value of the dipole moment due to interstrand eddy currents in these and similar magnets is relatively high compared to the higher order harmonics (see Table I). The field errors in Table I are related to the components of the 2-dimensional complex expansion of the field $\mathbf{B}$ in the magnet cross section as:

$$
B_{y}+i B_{x}=\sum_{n=1}^{\infty} C_{n}\left(\frac{z}{R_{\text {ref }}}\right)^{n-1}
$$

According to (1) the components $C_{n}$ give the field errors in Tesla at the reference radius $R_{r e f}$. Here $\mathrm{n}$ is the harmonic number and $\mathrm{z}=\mathrm{x}+$ iy is the complex position vector.

To calculate the contact resistance distribution from the field errors we first establish the relation between the field harmonics and the $\mathrm{R}_{\mathrm{C}}$ for each single cable in the magnet [1]. This relation can be put in the form $\mathrm{b}^{\perp}=\mathrm{MG}_{\mathrm{C}}{ }_{\mathrm{C}}$. Here $\mathrm{b}^{\perp}$ is the field error vector, $\mathrm{G}_{\mathrm{C}}(=1 / R c)$ is the crossing contact conductance vector and $M$ is a matrix. Knowing the measured field errors we then find the unknown $G_{C}$ distribution by minimizing $\left|\mathrm{b}_{\mathrm{m}}^{\mathrm{r}}-\mathrm{MG}{ }_{\mathrm{C}}^{\mathrm{r}}\right|^{2}$ where $\mathrm{b}_{\mathrm{m}}^{\perp}$ is the measured field error vector. Since the number of parameters (cables) is often larger than the number of measured harmonics we derive in this case a solution by simultaneously minimizing the standard deviation of the $G_{c}$ distribution. The solution found in this way is unique, but depends on the weighing factor applied to the standard deviation, and must be chosen so that 
TABLE II

COMPARISON OF RC VALUES (M $\Omega$ ) DERIVED FROM LOSS AND FROM FIELD MEASUREMENTS.

The apertures are marked Ap1 and Ap2, the two poles 'upper' and 'lower'.

\begin{tabular}{lllllllll}
\hline Magnet & $\begin{array}{l}\text { Loss } \\
\text { Field }\end{array}$ & & & & $\begin{array}{l}\text { Ap1, } \\
\text { upper }\end{array}$ & $\begin{array}{l}\text { Ap1, } \\
\text { lower }\end{array}$ & $\begin{array}{l}\text { Ap2, } \\
\text { upper }\end{array}$ & $\begin{array}{l}\text { Ap2, } \\
\text { lower }\end{array}$ \\
\hline MTP1A1 & Loss & 1.6 & 1.3 & 2.1 & 1.5 & 1.2 & 2.2 & 1.9 \\
& Field & - & 0.9 & - & 1.0 & 0.7 & - & - \\
MTP1A2 & Loss & 6.5 & 6.4 & 6.5 & 6.3 & 6.5 & 7.2 & 6.0 \\
& Field & - & - & 9.3 & 7.1 & 5.8 & 7.2 & 13.1 \\
MTP1A3 & Loss & 14.0 & 14.7 & 13.2 & 16.5 & 13.3 & 13.1 & 13.4 \\
& Field & - & & & 19.2 & 12.1 & - & - \\
MTP1N1 & Loss & 4.2 & 4.2 & 4.2 & 4.3 & 4.0 & 4.3 & 4.0 \\
& Field & - & - & - & - & - & - & - \\
MTP1N2 & Loss & 6.7 & 6.4 & 7.0 & 6.1 & 6.8 & 7.3 & 6.8 \\
& Field & 6.8 & 8.0 & 5.9 & 6.0 & 12.0 & 7.1 & 5.0 \\
\hline
\end{tabular}

$\left|\mathrm{b}_{\mathrm{m}}^{\mathrm{r}}-\mathrm{MG}{ }_{\mathrm{r}}^{\mathrm{r}}\right|^{2}$ remains sufficiently small. The main field component is always large but it was not always measured for all magnets. When it was not available we set the average contact resistance during the minimization procedure, equal to the one determined from loss measurements. The contribution to the field error from the outer layer cable is small due to the lower average field in this layer. Therefore these cables were grouped together in two blocks(B1 and B2 in Fig. 1), with constant $R_{C}$. Similar attempts to derive the $\mathrm{R}_{\mathrm{C}}$ distribution were performed on SSC magnets[12].

A. Average contact resistance of magnet

In Table II we compare for both methods the measured average contact resistance in five $10 \mathrm{~m}$ long, 2 -aperture dipole models. There is a reasonable agreement between the two measurements considering that the loss measurements give averages over the whole $10 \mathrm{~m}$ long magnet while the field measurements are performed over 1 or 2 lengths of $0.75 \mathrm{~m}$ of the magnet. In general the field measurements give larger differences in $\mathrm{R}_{\mathrm{C}}$ for the poles then the loss measurements. This may be because the mutual inductance of the poles influences the voltage measured on the poles during the loss measurement.

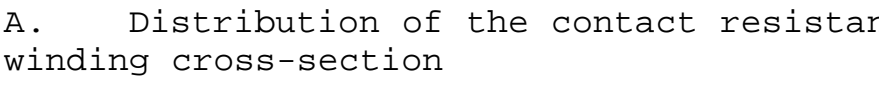

The distribution of $\mathrm{G}_{c}(=1 / \mathrm{Rc})$ can be quite dissimilar for the same magnet. This is illustrated in Fig. 2 for a measurement at the same longitudinal position in the two apertures of a $10 \mathrm{~m}$ model magnet. However the distribution of $\mathrm{G}_{\mathrm{C}}$ over the length of a magnet seems to be similar. This can be seen from the measurement of magnet MTP1N2 taken 1.50m apart (Fig. 2 and Table III, position 1 and 2 ).

We could not find any systematic pattern in the $G_{C}$ distribution of the four $10 \mathrm{~m}$ model magnets measured. This is perhaps not surprising since these magnets where the first of this kind to be constructed and came from different manufacturers and used different cables. Furthermore each magnet coil was manufactured and cured separately.

To study the distribution of the contact conductance we determined the average values and their standard deviation for the inner layer cable of each magnet pole (Table III). This shows that the difference between poles is of same order as the standard deviation within a pole cable.

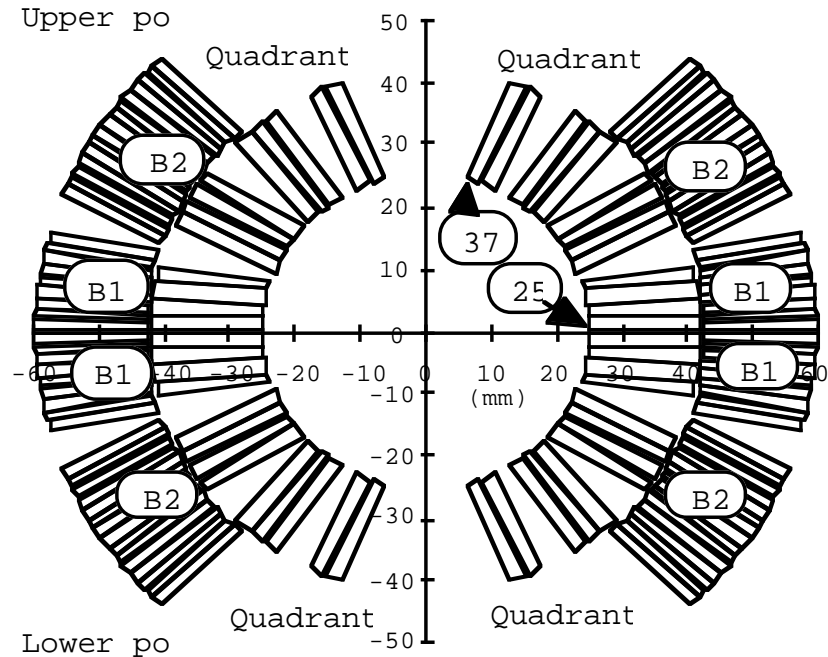

Fig. 1. A cross-section of the magnet coil of one aperture of the LHC $10 \mathrm{~m}$ model dipole. The coil consists of an outer and an inner winding wound with a different cable. Shown are the names given to the coil regions (B1, B2) and cables (25-37) for the Rc distribution calculations.
TABLE III.

DISTRIBUTION OF CONTACT CONDUCTANCE GC (=1/RC) IN THE INNER LAYER CABLES.

$\mathrm{Gc} 1, \sigma 1$ is the conductance and its standard deviation for the upper pole cable, $\mathrm{Gc} 2, \sigma 2$ for the lower pole. Note that $1 \mathrm{MS}=1(\mu \Omega)$

\begin{tabular}{lllllll}
\hline Magnet & Remark & $\begin{array}{l}\text { Gc1 } \\
(\mathrm{MS})\end{array}$ & $\begin{array}{l}\sigma 1 \\
(\mathrm{MS})\end{array}$ & $\begin{array}{l}\mathrm{Gc2} \\
(\mathrm{MS})\end{array}$ & $\begin{array}{l}\sigma 2 \\
(\mathrm{MS})\end{array}$ & $\begin{array}{l}\text { Gc1-Gc2 } \\
(\mathrm{MS})\end{array}$ \\
\hline MTP1A1, Ap1 & $\begin{array}{l}\text { over one } \\
\text { twist pitch }\end{array}$ & 1.158 & 0.805 & 1.558 & 0.718 & -0.400 \\
MTP1A2, Ap1 & $\begin{array}{l}\text { over 1.5m } \\
\text { length }\end{array}$ & 0.135 & 0.043 & 0.167 & 0.038 & -0.033 \\
& & & & & \\
MTP1A2, Ap2 & $1.5 \mathrm{~m}$ & 0.133 & 0.024 & 0.065 & 0.028 & 0.068 \\
MTP1A3, Ap1 & & 0.051 & 0.021 & 0.083 & 0.016 & -0.032 \\
MTP1N2, Ap1 & position 1 & 0.158 & 0.065 & 0.080 & 0.048 & 0.078 \\
MTP1N2, Ap1 & position 2 & 0.171 & 0.060 & 0.070 & 0.069 & 0.101 \\
MTP1N2, Ap2 & position 1 & 0.137 & 0.036 & 0.175 & 0.050 & -0.039 \\
MTP1N2, Ap2 & position 2 & 0.156 & 0.048 & 0.208 & 0.053 & -0.052 \\
\hline
\end{tabular}




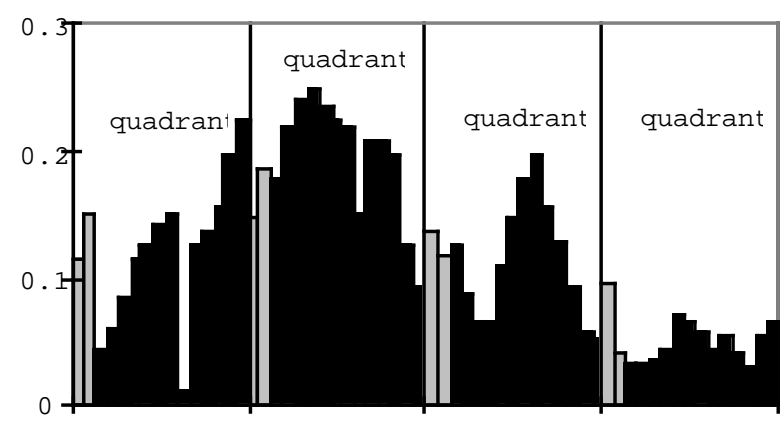

B1 $28 \quad 33 \quad{ }^{B} 1_{C a b l e} 33$ and $B 10$ lock 33 ind ${ }^{2} 128 \quad 33$

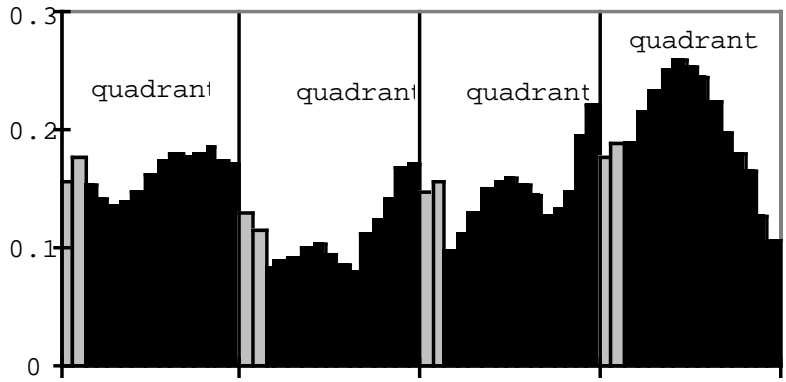

B1 273135 B2c28832 36 25229 $33 \begin{array}{llll}37 & 26 & 30 & 34\end{array}$

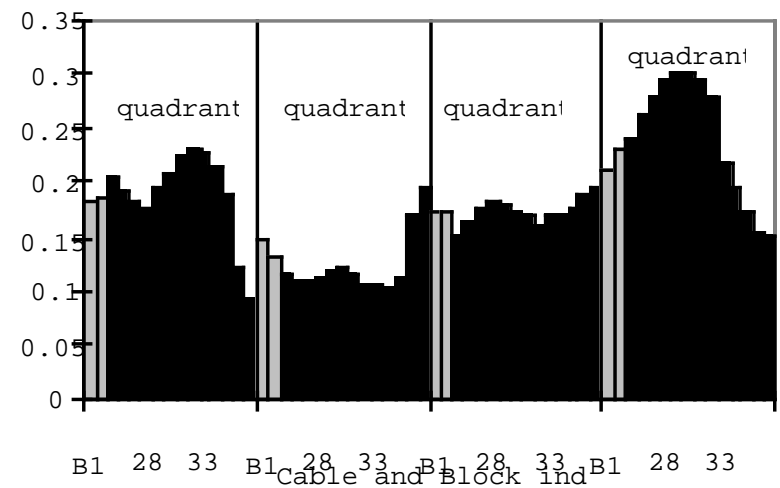

Fig.2. Distribution of the contact conductance $\mathrm{Gc}\left(=1 / \mathrm{R}_{\mathrm{C}}\right)$ in magnet MTP1N2, in Aperture 1 (above) and Aperture 2 (middle and below), over lengths of $0.75 \mathrm{~m}$. The two $\mathrm{G}_{\mathrm{C}}$ distributions in Aperture 2 were measured $1.5 \mathrm{~m}$ apart. The distribution is given for the cables of the inner coil layer (black) and for the cable blocks of the outer layer(grey), see also Fig. 1.

A. Power loss distribution in the windinc Knowing the $\mathrm{R}_{\mathrm{C}}$ distribution we can also easily derive the power distribution in the windings(Fig. 3) for a given ramprate. This could be useful as a tool to study quenching of the magnet during rapid field changes.

\section{COMPARISON WITH MEASUREMENTS ON SHORT CABLE SAMPLES}

The contact resistance $R_{C}$ between crossing strands is controlled by the resistive barrier surrounding a strand [4]. The contact surface area does not vary significantly between the measured cables, and therefore does not modify $R_{C}$. A thin layer of oxides or other compounds, often semiconducting, created on the surface of a strand, is a very efficient barrier.

Unfortunately, in the course of the production, magnet coils have to be cured, i.e. sized and glued at elevated temperature and pressure. The curing temperature ranges between 160 and $190 \mathrm{C}$, and the pressure can be up to $100 \mathrm{MPa}$.

During curing the micro-contacts close hermetically, and the oxide barrier is dispersed due to the elevated temperature, hereby diminishing $\mathrm{R}_{\mathrm{C}}$. If in the finished coil, the contacts release during storage, a new barrier forms that may increase $\mathrm{R}_{\mathrm{C}}$.

If the micro contacts do not close hermetically during the curing, additional barrier may form on their surface, which increases $R_{C}$. We observed on the cables with $\mathrm{SnAg}$ coated strands that the increase in $R_{C}$ due to the curing without pressure is equivalent to the increase in $R_{C}$ due to the curing at full pressure, followed by a pressure release, while the temperature, and the curing time are the same [4].

As shown in [4] both the decrease and the increase of $R_{C}$ are sensitive to the curing temperature. They are less sensitive to the curing pressure.

As a result of the condition of the contacts during and after curing, three levels of $R_{C}$ can be expected in a magnet coil:

- $\quad$ a small $\mathrm{R}_{\mathrm{C}}$ due to dissolution of the resistive barrier,

- $\quad$ an $\mathrm{R}_{\mathrm{C}}$ larger than $\mathrm{R}_{\mathrm{C}}$ of the virgin cable, if the contacts were not closed during curing, or relaxed after curing,

- $\quad$ an $\mathrm{R}_{\mathrm{C}}$ equal to that of the virgin cable. This can happen occasionally in cables with particular SnAg coating.

In Table IV we compare the $\mathrm{R}_{\mathrm{C}}$ of 12 model LHC magnets with $R_{C}$ measured on samples of cables. Parameters of these magnets are given in [7], [8], [9].

The values of $R_{C}$ in magnets are based on our loss measurements. To measure the values of $R_{C}$ in samples of cables we used a DC method described in [4]. Only the inner layer cables are compared, since the inner layer of the magnet coil gives the main contribution to the measured loss.

The samples of cable measured by the DC method were prepared from the same cables, as were used in the magnets. The samples were measured 1) as received, 2) after a curing, equivalent to the curing of the magnet in which this cable was used, and 3) after curing and after the pressure on the sample was released and reapplied. The decrease of $R_{C}$ after curing in cable samples means that the contacts were

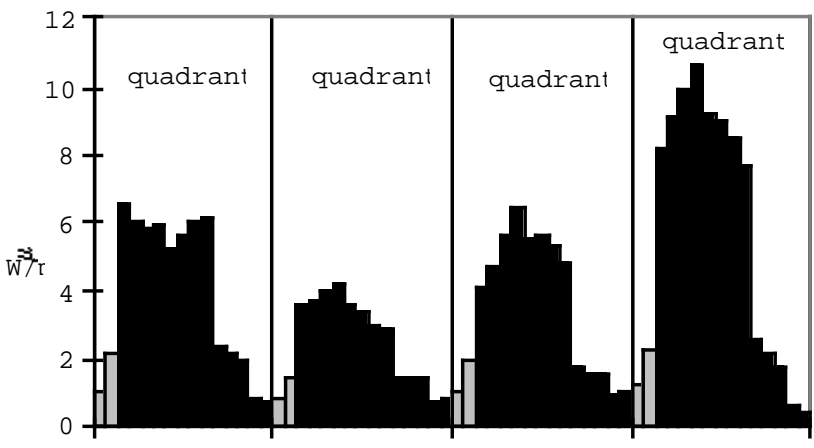

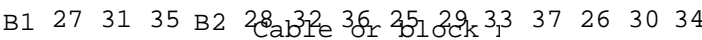

Fig. 3. The power distribution in magnet MTP1N2, Aperture 2, average over a length of $0.75 \mathrm{~m}$. 
TABLE IV

COMPARISON BETWEEN THE RC VALUES MEASURED IN MAGNETS AND ON SHORT SAMPLES OF CABLE.

The $R_{C}$ values for cables printed in italic have been extrapolated based on analogous measurements. The cable samples were cured under conditions equivalent to the curing of the magnet in which this cable was used.

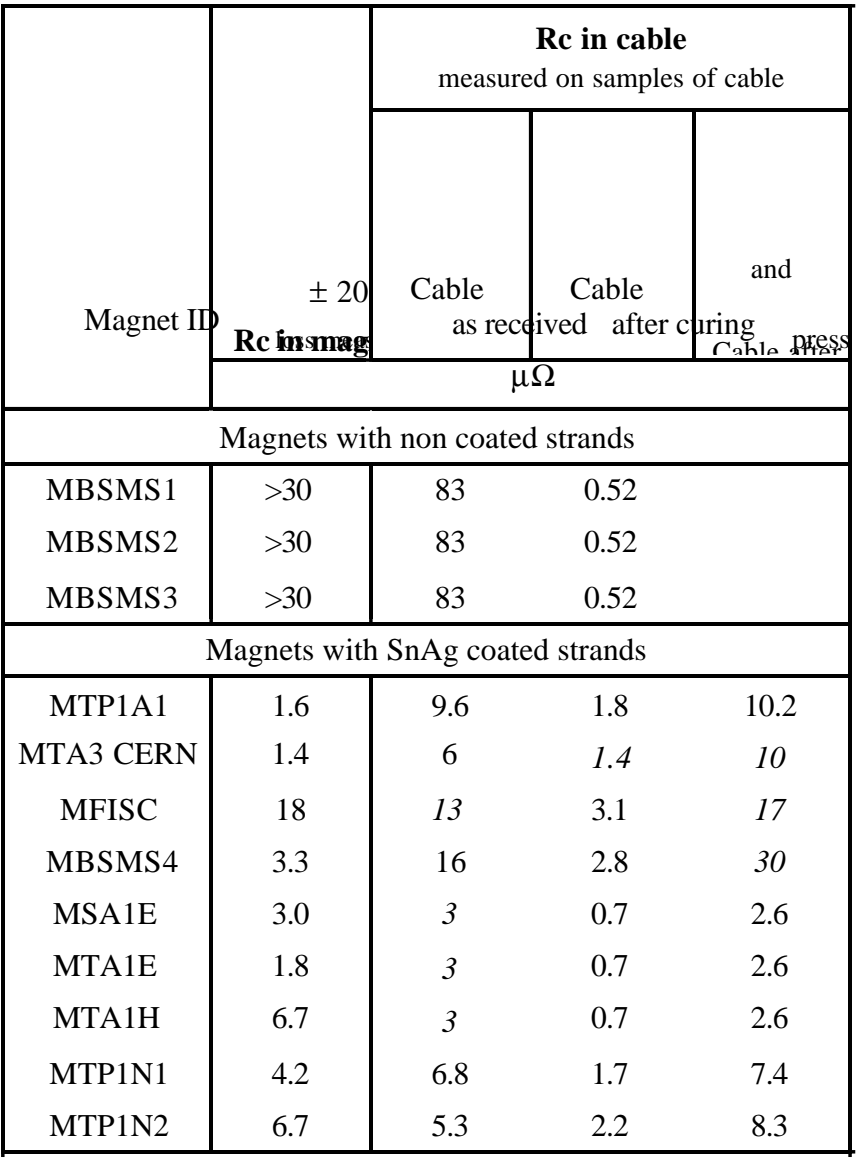

hermetically closed during curing.

The $R_{C}$ values in the magnets MBSMS1, MBSMS2, MBSMS3 were too high to be evaluated by the loss measurement method. From the field measurements we derived $\mathrm{R}_{\mathrm{C}}=40 \mu \Omega$. The difference between the estimated lower limit of $R_{C}$ in magnets, and $R_{C}$ measured on samples of cable after curing suggests that the contacts were not hermetically closed during a part of the curing.

$\mathrm{R}_{\mathrm{C}}$ measured in the magnets MTP1A1, MTA3CERN, and MBSMS4 corresponds to $R_{C}$ measured on cable samples after curing. That means that the contacts were hermetically closed during all the curing.

$\mathrm{R}_{\mathrm{C}}$ measured in the magnets MFISC, MSA1E, MTP1N1, and MTP1N2 corresponds to $R_{C}$ measured on cable samples after pressure relaxation. This suggests that the contacts were not hermetically closed during a part of the curing.

$R_{C}$ measured in the magnet MTA1E is between $R_{C}$ for the cable just after curing, and $R_{C}$ for the cable after pressure release. This could mean that part of the contacts were closed during the curing, while the rest remained open.

\section{CONCLUSION}

There is a good correlation between the average $R_{C}$ of a magnet determined from field and loss measurements. We could not find a systematic pattern in the $R_{C}$ distribution in the coils of the four model magnets studied. The distribution does not seem to change much over the length of the magnet.
We found that it is possible to understand the average $R_{C}$ in the magnets from the $R_{C}$ measured on cable samples. It seems that in 8 of the 12 compared magnets the interstrand contacts were open during curing. In 3 magnets the contacts may have been closed during curing.

The next step is to understand the $\mathrm{R}_{\mathrm{C}}$ distribution inside the coils, as well as the difference in evolution of the average $\mathrm{R}_{\mathrm{C}}$ between magnets, and correlate them to the coil manufacturing.

\section{REFERENCES}

[1] A. P. Verweij, R. Wolf, "Field Errors due to Interstrand Coupling Currents in the LHC Dipole and Quadrupole", CERN/ATMA internal note 94-97, March, 1994

[2] L Bottura, A Faus-Golfe, L. Walckiers, R. Wolf, "Field Quality of the Main Dipole Magnets for the LHC Accelerator", Presented at the European Particle Accelerator Conference, Sitges, Spain, June, 1996.

[3] A.P.Verweij, Electrodynamics of Superconduc Accelerator Magnets, Ph.D., Twente University (NI

[4] D. Richter, J., D. Adam, J-M. Depond, D. Leroy,. R. Oberli, Cern, "Dc Measurement Of Electrical Contacts Between Strands In Superconducting Cables for the LHC Main Magnets", Presented at 1996 Applied Superconductivity Conference, Pittsburgh, U.S.A, August 25-30, 1996

[5] J-M. Depond, D. Leroy, L. R. Oberli, D. Richter, "Examination Of Contacts Between Strands By Electrical Measurement and Topographical Analysis", Presented at the Applied Superconductivity Conference, Pittsburgh, U.S.A, August 25-30, 1996.

[6] The Large Hadron Collider - Conceptual Design, CERN/AC/9505, 1995.

[7] R. Perin, "Status of the Large Hadron Collider Magnet Development”, IEEE Trans. On Magn., 30, 4, 1579-1586, 1994.

[8] R. Perin, "Status of the LHC programme and Magnet Development", IEEE Trans. On Appl. Sup., 5, 2, 189-195, 1995.

[9] N. Siegel, "Status of the Large Hadron Collider and Magnet Program", Presented at 1996 Applied Superconductivity Conference, Pittsburgh, U.S.A, August 25-30, 1996.

[10] A. P. Verweij, D. Leroy, L. Walckiers, R. Wolf, "Analysis of the AC loss measurements on the One-Meter dipole model magnets for the CERN LHC", IEEE Trans. On Magn., 30, 4, 1758-1761, 1994.

[11] J. Buckley, D. Richter, L. Walckiers, R. Wolf, "Dyr Magnetic Measurements of Superconducting Magnets IEEE Trans. Appl. Sup., 5, 2, 1024-1027, 1995

[12] A. Devred, T. Ogitsu, "Ramp-Rate Sensitivity of SSC Dipole Magnet Prototypes”, KEK Preprint 94-156, December, 1994. 